\title{
The ethics of egg manipulation
}

\author{
Cell research reopens the debate on embryo destruction, egg donation and what is natural.
}

V any couples are faced with the unpleasant choice between not having a child of their own and risking the passing on of a debilitating disease. Yet research into reproductive technologies to lessen the chances of having unhealthy babies has been hampered by public attitudes to interfering with the course of life.

Mutations in the DNA of mitochondria - energy-producing organelles in a cell - are linked to a growing list of diseases, and treatment options tend to be limited to the alleviation of symptoms. In theory, the mutations could be picked up by the early screening of embryos, but efforts to do so have been of limited value, in part because little is known about how much mitochondrial damage is needed to cause disease.

Now, a paper published online by Nature this week (M. Tachibana et al. Nature doi:10.1038/nature $08368 ; 2009)$ offers a way to eliminate the problem. The technique involves taking the nuclear DNA from one egg cell and transferring it to another egg that has had its nucleus removed. The newly 'reconstructed' egg will then contain mitochondria only from the new egg cell, leaving behind any defective mitochondria from the original cell. It can then be used for in vitro fertilization.

But the work presented this week is done in monkeys. Demonstrating that it can be done safely in humans will require research that is likely to be contentious - and, in many countries, legally or practically impossible.

One major roadblock is that human embryos will need to be created solely for research, which many people feel violates the sanctity of human life. That argument was used by the administration of former US President George Bush to restrict such studies, and even now the National Institutes of Health and other US agencies cannot fund them. Still, this obstacle it hasn't stopped research from being funded by non-federal sources, such as the state of California. Nor has it kept embryos from being created then destroyed in the course of commercial fertility treatments.

A more serious roadblock is the difficulty in obtaining the human eggs needed for both donor and recipient cells in the nuclear-transfer procedure. The egg-donation procedure is uncomfortable and somewhat risky, and some bioethicists argue that compensating women who undergo it is tantamount to a form of coercion. Paid egg donation for research is prohibited by most state and federal funding agencies in the United States and elsewhere (with the notable exception of New York state, which allows it).

As a result, egg cells are generally available only from women who are willing to give them altruistically — a comparatively small number, made smaller by the fact that women can get thousands of dollars for donating to a fertility clinic. Thus, research in some fields, such as somatic-cell nuclear transfer, or cloning, has slowed almost to a halt.

More states should take New York's lead, and allow researchers to pay for egg donation. The potential for coercion, although real, is manageable. And the technique's move to the clinic would certainly be faster, and arguably more ethical, if donors were paid (C. Thompson Regen. Med. 2, 203-209; 2007).

Yet another argument raised when such research has been attempted in the past - for example when researchers tried to replenish damaged mitochondrial DNA in one egg with healthy mitochondrial DNA from another - is that such a three-parent union is 'unnatural'. Yet similar concerns greeted in vitro fertilization when it was being pioneered in the 1970s, and the technique is now widely accepted. Blanket bans can impede progress and encourage unethical practices. With appropriate oversight, research into other reproductive technologies has the potential to give more couples the chance of having a healthy baby.

\section{All the news you need}

T his issue marks an evolution in Nature's news coverage. On page 1062, we are launching News Briefing - a two-page digest of the key events shaping the scientific enterprise in the past week. With coverage encompassing policy decisions, funding announcements, market trends and business deals, News Briefing offers a complete overview of the developments that affect anyone working in science. The section also features a calendar to highlight important events, reports and initiatives occurring in the forthcoming week.

Science is inextricably linked with the messy details of politics and commerce, and it is vital for today's researchers to be aware of how political and business decisions can steer their research programmes - and indeed how their research can affect society. Similarly, policy-makers require the perspective that science can provide on the likely outcomes of their decisions. Yet it is all too easy to miss something important in the torrent of news that pours down on us every day.

By gathering all of the important events in one place, News Briefing aims to plug that gap. In doing so, it complements Research Highlights, which for the past four years has brought you our editors' selections of the most interesting research results from beyond the pages of Nature. Both sections will guide you to longer analytical pieces and exclusives in the main news section or online at www.nature.com/news. Apart from breaking daily news stories, our news website also carries stories from the print edition before they make it onto paper, getting analysis and information to our subscribers as soon as possible.

The introduction of News Briefing to our family of daily online coverage and weekly analysis means that Nature now provides a complete overview of the important events shaping our readers' lives. As ever, we would welcome any feedback on the changes, which should be sent to nature@nature.com. 